\title{
Corticoides: efectos secundarios oculares
}

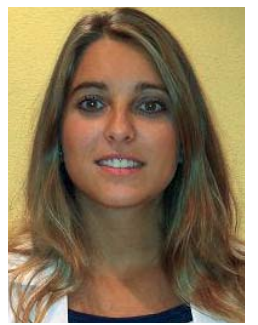

Lucía de Pablo Gómez de Liaño

Médico residente de Oftalmología. Hospital Universitario 12 de Octubre. Madrid.

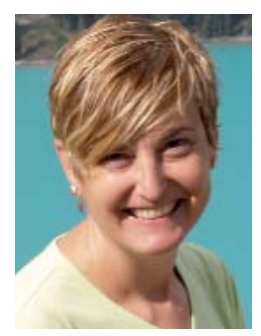

Marta Montero Rodríguez Médico adjunto de Oftalmología. Hospital Universitario 12 de Octubre. Madrid.

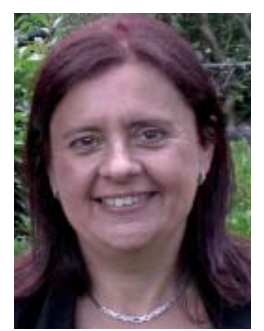

Esperanza Gutiérrez Díaz

Jefe de sección de Oftalmología. Hospital Universitario 12 de Octubre. Madrid.

\section{INTRODUCCIÓN}

Los corticoides tópicos son los medicamentos más comúnmente prescritos en dermatología, tanto por vía sistémica como tópica. Se utilizan por su efecto antiinflamatorio, vasoconstrictor y sus propiedades inmunosupresoras. Los diferentes vehículos de la formulación también contribuyen a mejorar la potencia de un esteroide tópico particular. Se considera que los ungüentos son más potentes que las cremas, lociones o soluciones. Dos son los efectos secundarios que pueden producir los corticoides a nivel ocular: glaucoma y catarata.

\section{GLAUCOMA CORTICOIDEO}

El glaucoma es una neuropatía óptica que consiste en la excavación y socavamiento de los elementos nerviosos y el tejido conectivo de la papila óptica (cabeza del nervio óptico), así como el consiguiente desarrollo de defectos del campo visual, en cuyo desarrollo influyen muchos factores, uno de ellos es el aumento de la presión intraocular $(\mathrm{PIO})^{1}$.

El glaucoma corticoideo es un glaucoma de ángulo abierto causado por el uso de corticosteroides, por vía tópica (cremas, pomadas, colirios, etc.), sistémica, por inhalación o por inyección subconjuntival o intravítrea. La vía de administración que más se asocia al aumento de la presión intraocular es la vía tópica ${ }^{1}$.
Aproximadamente un tercio de pacientes muestra cierta sensibilidad a los corticosteroides, pero solo un pequeño porcentaje va a desarrollar una elevación de la PIO clínicamente significativa. Dicho aumento tensional puede causar, en algunos pacientes, una lesión glaucomatosa del nervio óptico ${ }^{2}$ (fig. 1).

Es ampliamente conocido que la PIO fluctúa a lo largo del día y se ha postulado que esto puede estar relacionado con los niveles de cortisol en sangre. El pico máximo se produce alrededor de las $7.00 \mathrm{~h}$ y el valle durante la tarde. Además, en los pa-
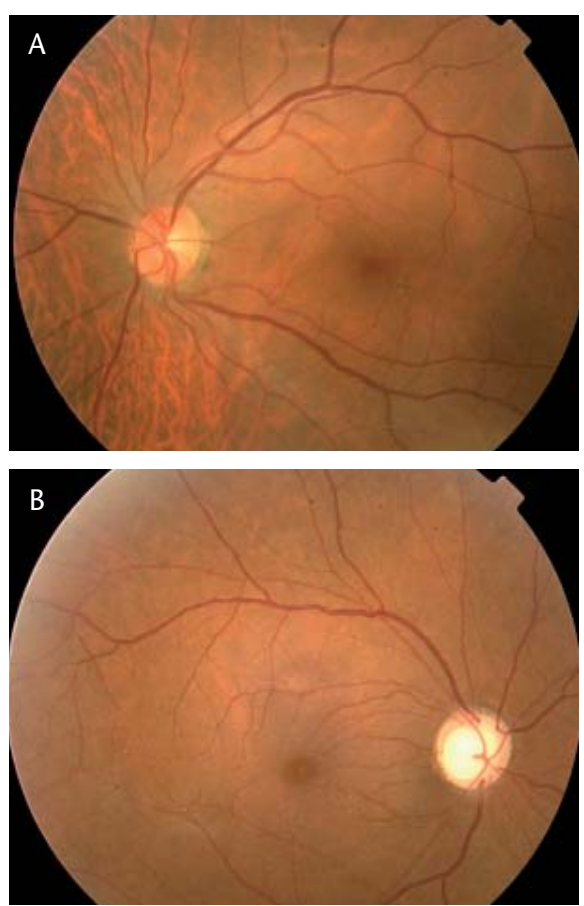

Figura 1. Imagen de papila normal (A) y papila glaucomatosa (B). 
cientes sin glándulas adrenales, no hay variación en los niveles de la PIO durante el día.

El tiempo de respuesta a los corticoides, así como la intensidad de la misma, van a depender del tipo, la potencia, la vía y la frecuencia de administración del fármaco, así como de la susceptibilidad del paciente a dichos fármacos².

\section{Mecanismo}

El humor acuoso se produce en la cámara posterior, circula a través de la pupila hacia la cámara anterior y es drenado del ojo por dos vías diferentes: la vía trabecular (90\% del drenaje), que, desde el trabeculum, drena hacia el canal de Schlemm y de ahí a las venas epiesclerales, y la vía uveoescleral $(10 \%)$, por la que, a través del cuerpo ciliar, el humor acuoso pasa hacia el espacio supracoroideo y es drenado por la circulación venosa de la coroides y la esclerótica. El aumento de la PIO se debe a un aumento de la resistencia al drenaje del humor acuoso en la malla trabecular-canal de Schlemm, debido a la inhibición de la degradación del material de la matriz extracelular en la malla trabecular.

Existe además una susceptibilidad genética para el desarrollo del glaucoma corticoideo ${ }^{4}$.

\section{Factores de riesgo ${ }^{2}$}

- Edad $<6$ años.

- Edad avanzada.

- Diabetes.

- Enfermedades del tejido conectivo.

- Glaucoma o antecedentes familiares de glaucoma; mientras que la terapia crónica corticoidea produce hipertensión ocular en aproximadamente un tercio de individuos, la mayoría de los pacientes con glaucoma primario muestra esta respuesta.

- Antecedentes de respuesta previa.

- Miopía elevada.

- Uso crónico de corticoides: si bien es cierto que el glaucoma esteroideo aparece tras la administración crónica de corticoides, el aumento de la presión intraocular puede aparecer desde el pri- mer día de su uso (sobre todo en niños) hasta semanas después, siendo esto último lo más frecuente, por eso debe vigilarse la PIO regularmente en estos pacientes ${ }^{5}$. Aquellos pacientes que usan corticosteroides durante más de 4 años tienen PIO significativamente más altas que los que lo usan durante menos de 1 año.

\section{Preparaciones}

Algunos productos como fluorometolona, rimexolona o medrisona tienen menos tendencia a elevar la PIO que la prednisona o la dexametasona.

Cuando no se puede evitar la terapia esteroidea, deberemos usar aquel fármaco con el suficiente efecto terapéutico, a la menor dosis posible y con los menores efectos secundarios.

\section{Manejo del glaucoma corticoideo ${ }^{2}$}

- Monitorización de la PIO:

Debe tomarse siempre una medida basal de la PIO antes de comenzar la terapia corticoidea, sobre todo en los niños. En pacientes con terapia tópica, se debería tomar la PIO de nuevo a las 2 semanas tras el inicio del tratamiento, después cada 4 semanas durante 2-3 meses y controles posteriores cada 6 meses si la terapia continúa. Idealmente, los pacientes que requieren corticosteroides sistémicos durante un largo período de tiempo deberían someterse a un cribado de glaucoma y aquellos que reciben $10 \mathrm{mg}$ o más de prednisona al día deberían comprobar la PIO al mes, a los 3 y a los 6 meses después de iniciado el tratamiento y posteriormente cada 6 meses. El cribado de glaucoma puede ser realizado por los optometristas u oftalmólogos de los centros de especialidades.

- Cese del tratamiento corticoideo:

Retiraremos el tratamiento si el paciente presenta glaucoma o si existe progresión del mismo. Tras suspender el uso de corticoides, la PIO suele tardar en normalizarse aproximadamente tanto tiempo o más de lo que tardó en aparecer la hipertensión. Si no es posible suspender la 
terapia, deben considerarse otros métodos para reducir los efectos adversos.

- Alternativas de tratamiento:

El tratamiento tópico puede cambiarse por productos como la fluorometolona, que tienen menos efectos sobre la PIO, o sustituirse por antiinflamatorios no esteroideos. El tratamiento sistémico puede ver disminuidos sus efectos secundarios mediante la introducción de agentes ahorradores de esteroides, como la ciclofosfamida o el metotrexato.

- Glaucoma irreversible inducido por esteroides: Aparece en el 3\% de los casos, especialmente cuando existe historia familiar de glaucoma o uso crónico de esteroides (> 4 años).

- Terapia antiglaucomatosa:

Existen varios grupos de fármacos para el tratamiento de la hipertensión ocular: betabloqueantes, prostaglandinas, alfaagonistas, inhibidores de la anhidrasa carbónica, etc. En los pacientes con aumento de la PIO que no responden a la terapia médica, el tratamiento quirúrgico alcanza una elevada tasa de éxitos.

\section{CATARATA CORTICOIDEA 6}

La opacificación del cristalino puede localizarse en distintos lugares anatómicos del mismo. En función de esta localización, existen tres tipos principales de cataratas: nuclear, cortical y subcapsular posterior (fig. 2).

El uso prolongado de corticosteroides puede ocasionar una catarata subcapsular posterior (SCP), cuya incidencia depende de la dosis y de la duración del tratamiento. Se ha descrito la formación de catarata tras la administración de corticoides por distintas vías: sistémica, tópica, subconjuntival e inhalatoria. Tras el tratamiento corticoideo por vía sistémica, con dosis superiores a $15 \mathrm{mg} / \mathrm{d}$ de prednisona durante más de 1 año, existe una incidencia en su presentación mayor del 80\%. En cuanto a la vía tópica, puede aparecer tras la aplicación de preparados dermatológicos de corticoides alrededor de los párpados.
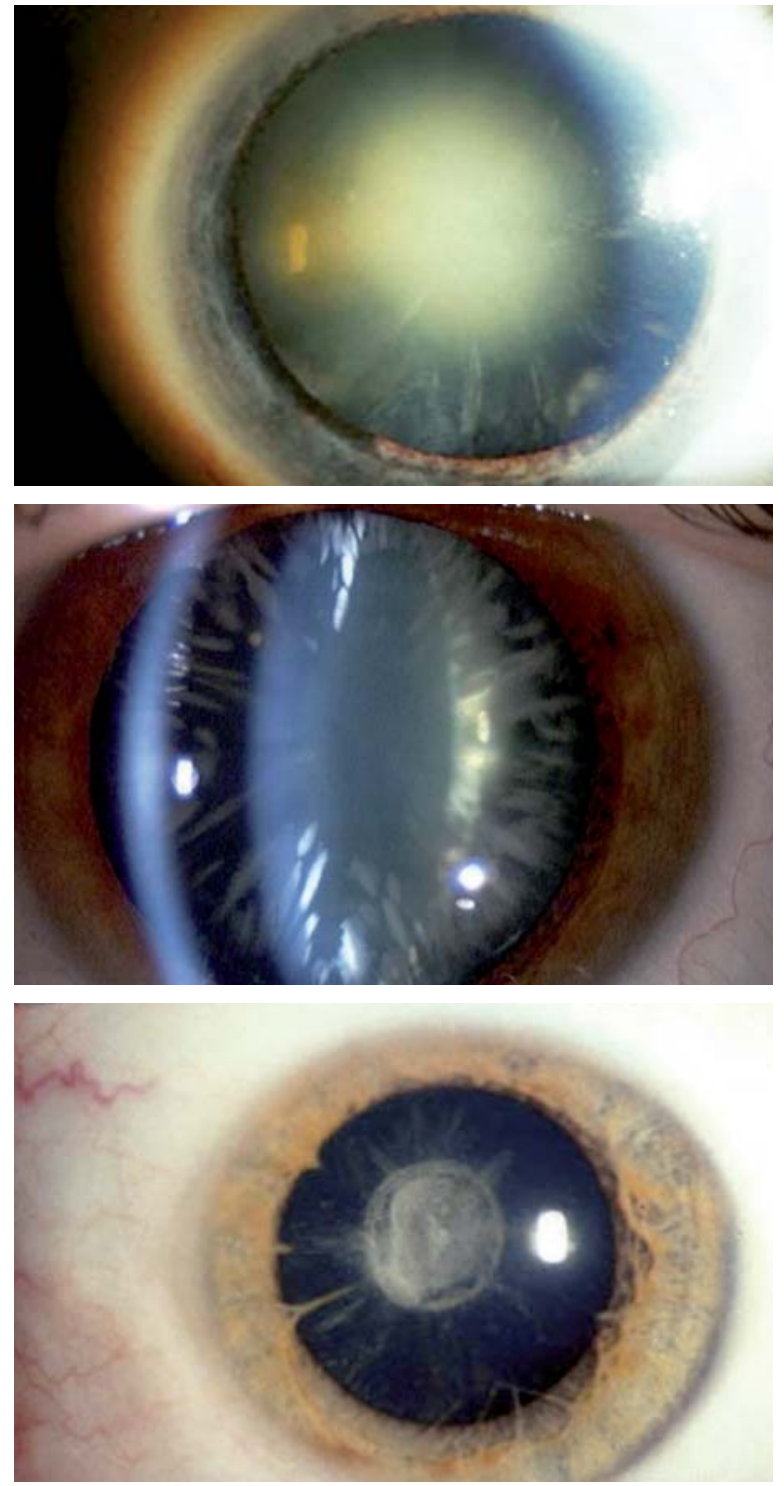

Figura 2. Imágenes de catarata nuclear, cortical y subcapsular posterior en forma de placa.

La catarata SCP se sitúa en la capa cortical posterior del cristalino y aparece como opacidades granulares o en forma de placa. Este tipo de catarata afecta más a la visión que la catarata nuclear o cortical. Desde el punto de vista histopatológico y clínico, la aparición de la catarata SCP no difiere de la formación de la catarata senil.

Los pacientes sensibles al aumento de PIO inducido por esteroides suelen ser aquellos que experimentan catarata SCP. 
En los niños, algunas de las cataratas SCP inducidas por corticoides remiten al suspender la medicación. El resto se consideran irreversibles y precisan cirugía para su eliminación.

\section{Síntomas}

El paciente se queja de deslumbramiento y mala visión en condiciones de iluminación brillante. La agudeza visual de cerca tiende a reducirse más que la lejana. Algunos pacientes refieren diplopia monocular. Otros síntomas son: disminución de contrastes y cambios en la percepción del color.

- Catarata y enfermedades cutáneas:

Se ha descrito la aparición de catarata hasta en un $25 \%$ de los pacientes con dermatitis atópica, independientemente del tratamiento con corticoides. Suelen ser bilaterales y comienzan en la segunda o tercera década de la vida. En general, estas cataratas son opacidades subcapsulares anteriores que remedan placas en forma de escudo.

\section{CONCLUSIONES}

- Los corticoides administrados de forma crónica, tanto por vía tópica como sistémica, tienen efectos oculares secundarios; por ello, es preciso rea- lizar revisiones oftalmológicas periódicas en estos pacientes.

- Al prescribir los corticosteroides, hay que tener en cuenta la potencia, el vehículo, la superficie de aplicación, el tiempo de uso y los efectos adversos.

- El médico debe seleccionar un corticoide lo suficientemente potente para eliminar la dermatosis, pero lo menos potente posible para así evitar los efectos secundarios.

- En caso de establecerse el glaucoma corticoideo, debe suspenderse la corticoterapia.

- El único tratamiento eficaz para la catarata es la cirugía.

\section{BIBLIOGRAFÍA}

1. Cioffi G. American Academy of Ophthalmology; glaucoma. Vol 10. Barcelona: Elsevier; 2009. p. 120.

2. Kersey JP, Brodway DC. Corticosteroid induced glaucoma: a review of the literature. Eye. 2006;20:407-16.

3. Kanski J. Oftalmología clínica. 6a ed. Barcelona: Elsevier; 2009. P. 364-6.

4. Fingert J, Alward W, Wang K, Yorio T. Assessment of SNPs associated with the human glucocorticoid receptor in primary open-angle glaucoma and steroid responders. Mol Vis. 2010;16:596-601.

5. Tham CC, Ng JS, Li RT, Chik KW, Lam DS. Intraocular pressure profile of a child on a systemic corticosteroid. Am J Ophthalmol. 2004;137:198-201.

6. Bobrow J. American Academy of Ophthalmology. Cristalino y catarata. Barcelona: Elsevier; 2009. P. 47, 52. 